\title{
Field measurements of hygroscopic properties and state of mixing of nucleation mode particles
}

\author{
M. Väkevä ${ }^{1}$, M. Kulmala ${ }^{1}$, F. Stratmann ${ }^{2}$, and K. Hämeri ${ }^{3}$ \\ ${ }^{1}$ University of Helsinki, Department of Physical Sciences, Helsinki, Finland \\ ${ }^{2}$ Institute for Tropospheric Research, Leipzig, Germany \\ ${ }^{3}$ Finnish Institute of Occupational Health, Helsinki, Finland
}

Received: 14 October 2001 - Published in Atmos. Chem. Phys. Discuss.: 3 December 2001

Revised: 15 February 2002 - Accepted: 19 February 2002 - Published: 27 February 2002

\begin{abstract}
An Ultrafine Tandem Differential Mobility Analyser (UF-TDMA) has been used in several field campaigns over the last few years. The investigations were focused on the origin and properties of nucleation event aerosols, which are observed frequently in various environments. This paper gives a summary of the results of $10 \mathrm{~nm}$ and $20 \mathrm{~nm}$ particle hygroscopic properties from different measurement sites: an urban site, an urban background site and a forest site in Finland and a coastal site in western Ireland. The data can be classified in four hygroscopic growth classes: hydrofobic, less-hygroscopic, more-hygroscopic and sea-salt. Similar classification has been earlier presented for Aitken and accumulation mode particles. In urban air, the summertime $10 \mathrm{~nm}$ particles showed varying less-hygroscopic growth behaviour, while winter time $10 \mathrm{~nm}$ and $20 \mathrm{~nm}$ particles were externally mixed with two different hygroscopic growth modes. The forest measurements revealed diurnal behaviour of hygroscopic growth, with high growth factors at day time and lower during night. The urban background particles had growth behaviour similar to the urban and forest measurement sites depending on the origin of the observed particles. The coastal measurements were strongly affected by air mass history. Both $10 \mathrm{~nm}$ and $20 \mathrm{~nm}$ particles were hygroscopic in marine background air. The $10 \mathrm{~nm}$ particles produced during clean nucleation burst periods were hydrofobic. Diurnal variation and higher growth factors of $10 \mathrm{~nm}$ particles were observed in air affected by other source regions. External mixing was occasionally observed at all the sites, but incidents with more than two growth modes were
\end{abstract}

Correspondence to: K. Hämeri

(kaarle.hameri@occuphealth.fi) extremely rare.

\section{Introduction}

Tandem Differential Mobility Analyser (TDMA) instruments have been widely used for studies of hygroscopic properties of submicron aerosol particles. These measurements provide valuable information on the thermodynamic properties of submicron laboratory particles. In addition, also ambient aerosol particles have been characterised in various environments (e.g. McMurry and Stolzenburg, 1989; Svenningsson et al., 1992; Covert and Heintzenberg, 1993; Swietlicki et al., 1999). In the above referenced studies the focus was on particles in Aitken and accumulation modes. These are the size ranges most abundant in the measurement sites. Recently the presence of nucleation mode particles have been observed frequently in several locations (e.g. Mäkelä et al., 1997; O'Dowd et al., 1998; Birmili and Wiedensohler, 2000). However, the characterisation of the nucleation mode particles is a difficult task because of the small mass of these particles. A TDMA system provides means for chemical characterisation of the nucleation mode particles. Even though TDMA measurements alone will not give the exact composition of the aerosol particles, but represent only a pointer to a possible composition, they give information about the aerosol physico-chemical behaviour and state of mixing. This information can be used as input for aerosol dynamic models.

This study concentrates on the measurements of hygroscopic properties of nucleation mode particles with a TDMA. The field studies presented have a major focus on investigat- 
M. Väkevä et al.: Hygroscopicity of nucleation mode particles

ing the origin and properties of the freshly nucleated particles. In addition, the properties of background air nucleation mode particles are investigated. When categorising nucleation mode particles one should keep in mind the Kelvin effect: out of two particles with identical composition, the smaller one will have a smaller growth factor. A more detailed description of the growth of laboratory generated nucleation mode aerosol particles can be found in Hämeri et al. (2000) and Hämeri et al. (2001a). It should also be noted that the deliquescence properties of the nucleation mode particles are different from the larger particle sizes. For example for $\mathrm{NaCl}$ particles with $10 \mathrm{~nm}$ mobility diameter the deliquescence relative humidity is over $80 \%$, when for particles with diameters above $100 \mathrm{~nm}$ it is about $75 \%$ (Hämeri et al., 2001a; Djikaev etal., 2001). For this reason the ambient measurements should be conducted under a constant relative humidity as high as possible (in this study nominally 90\%) and it should be remembered that even though the bulk material of some substance is hygroscopic, a nucleation mode particle of the same composition might appear non-hygroscopic in the relative humidity studied.

In earlier work ambient submicron aerosol particles have been divided into four hygroscopic classes accordingly (e.g. Swietlicki et al., 2000): (1) Hydrofobic particles that do not grow at all when exposed to humid conditions. (2) Less hygroscopic particles that have growth factors smaller than pure salts, but show still a clear response to increased humidity. (3) More hygroscopic particles that grow similarly to common atmospheric inorganic salt (e.g. $\left.\left(\mathrm{NH}_{4}\right)_{2} \mathrm{SO}_{4}\right)$ particles. For the nucleation mode particles this means, for example, that particles having a dry diameter of $10 \mathrm{~nm}$ grow up to 13$14 \mathrm{~nm}$ or more at $90 \%$ relative humidity $\left(\left(\mathrm{NH}_{4}\right)_{2} \mathrm{SO}_{4}\right.$ grows up to about $13.8 \mathrm{~nm}$ ). (4) Sea salt particles. Growth factor of $\mathrm{NaCl}$ is often used as an indicator of this growth mode. For $10 \mathrm{~nm} \mathrm{NaCl}$ particles (produced with an atomizer), the growth factor at $90 \%$ relative humidity is about 1.8 .

It should be noted that Cocker etal. (2001) state that in urban air classification to these four classes is not enough. Their TDMA measurements of particles $50 \mathrm{~nm}$ and $150 \mathrm{~nm}$ in diameter revealed up to 6 simultaneous growth modes.

In this paper we present a summary of selected TDMA field experiments of $10 \mathrm{~nm}$ and $20 \mathrm{~nm}$ particles in mobility diameter from the years from 1997 to 1999 . The ambient observations presented here are from four different places: urban, urban background, and a forest site in Finland, and a coastal site in Western Ireland. The focus of the field studies has been primarily on the atmospheric new particle formation (the forest site, the coastal site and the urban background site). In addition the urban nucleation mode aerosols resulting largely from anthropogenic pollution sources are studied. The measurements at the forest site and the coastal site were conducted as parts of two EU projects (BIOFOR; PARFORCE) (see web sites at the end).

\section{Experimental}

\subsection{UF-TDMA}

The operation principle of an ultrafine tandem differential mobility analyzer (UF-TDMA) is similar to that of the TDMAs used to study hygroscopic properties of larger particle sizes. A more detailed description of the operation can be found in Hämeri et al. (2000). A quasi monodisperse size fraction of dried ambient aerosol particles is selected with a DMA, these particles are then humidified to a certain defined relative humidity, and a second DMA with humidified sheath flow is then used to monitor the changes in particle diameter. The change is expressed in terms of a growth factor $(G F)$, i.e. the ratio of the humid diameter to the dry diameter selected by the first DMA. There are, however, special requirements for an instrument devoted to study ultrafine, and especially nucleation mode, aerosol particles. (a) Because of the large diffusional losses of particles with diameters of the order of $10 \mathrm{~nm}$ the sampling lines and the transport through the instrument have to be short. (b) The often very low concentrations of ambient nucleation mode particles require high sensitivity in measuring particle concentrations. This requirement has been considered using a modified TSI 3010 CPC (with the temperature difference between the condenser and the saturator $25^{\circ} \mathrm{C}$ ). (c) The lower hygroscopic growth of the nucleation mode sized particles compared with larger particles due to Kelvin effect requires high sensitivity in determining the particle size. The diameters of both dry and humidified particles are determined using a Vienna type DMA with inner rod length of $11 \mathrm{~cm}, 1 / 10$ aerosol to sheath flow ratio, and dense voltage steps in the second DMA (e.g. Yuskiewicz et al., 1998).

\subsection{Data analysis}

To analyse the TDMA measurements a data inversion procedure is needed, i.e. from the concentration distribution $\Delta N\left(Z_{p, i}\right)$ measured downstream of DMA2 as a function of DMA2 midpoint mobility $Z_{p, i}$ the mobility distribution $n\left(Z_{p}\right)$ in front of DMA2 has to be determined. Concentrations downstream of DMA2 are described by

$\Delta N\left(Z_{p, i}\right) \approx \int_{0}^{\infty} n\left(Z_{p}\right) \Omega\left(Z_{p}, Z_{p, j}\right) d Z_{p}$

where $\Omega\left(Z_{p}, Z_{p, j}\right)$ is the DMA transfer function. Considering a sufficiently large number of measured mobilities discretization leads to

$\Delta N\left(Z_{p, i}\right) \approx \sum_{j} n\left(Z_{p, j}\right) \Omega\left(Z_{p, i}, Z_{p, j}\right) \Delta Z_{p}$,

The application of vector notation yields

$\overline{\Delta N}=\overline{\bar{\Omega}} \cdot \overline{n \Delta Z_{p}}$,

Consequently, the concentration distribution downstream of DMA2 is described by a set of linear equations. Solving 
this set with respect to $n$ yields the mobility distribution up-stream of DMA2. From this mobility distribution, the changes in particle mobility and consequently the growth factors can be determined.

For convenience, in this work two different techniques were used, (a) a method based on an inversion procedure featuring a numerical solution of Eq. 3 (e.g. Stratmann et al., 1997; Yuskiewicz et al., 1998), and (b) a simplified and less accurate procedure (Hämeri et al., 2001b).

The simplified procedure was used to determine the size into which particles had grown, by defining the size corresponding to the peak of the measurement spectra, and to get a rough estimate of the number of particles belonging to that spectrum. Then the more sophisticated algorithm was only used for a number of spectra to make sure the simple approach was trustworthy within the error limits of the measurement system, which are approximately $5 \%$ in changes in size.

With the two approaches the calculated diameters agreed well (well within the error limits of the measurements), but the errors in the estimated concentrations were larger. Typically the simple procedure gave about $10 \%$ smaller concentrations than the other one. Thus the concentrations measured with the UF-TDMA that are mentioned in this paper are mainly used as indicators of the presence of nucleation mode particles and as a rough means of comparing, e.g. relative amounts of externally mixed aerosol particles.

\subsection{Corrections of field data}

The UF-TDMA used in the described studies has been developed during the time period of the field campaigns. To be able to compare data measured during different field studies with different versions of the instrument, all data has been corrected based on calibration measurements. Ammonium sulphate particles generated with a nebulizer were used as the calibration aerosol.

It has been shown that laboratory measurements (Hämeri et al., 2000) and theoretical calculations do not give exactly the same growth factors for nucleation mode ammonium sulphate particles. Thus our field data has been corrected, (a) by first using a correction factor in order to make field $\left(\mathrm{NH}_{4}\right)_{2} \mathrm{SO}_{4}$ calibrations consistent with laboratory ammonium sulphate measurements (the "grown" part of the growth factor is multiplied with the correction factor presented in Eq. 4, i.e. $G F($ corrected $)=1+[G F$ (measured)-1] $*$ correction factor), and (b) then by correcting growth factors measured in other than the nominal $90 \%$ relative humidity by using fitted laboratory data.

The correction factor (a) was calculated as follows:

$\operatorname{corr}=\left(G F_{l a b}(R H)-1\right) /\left(G F_{\text {field }}(R H)-1\right)$,

where $G F_{\text {field }}$ is the growth factor of the ammonium sulphate calibration in the field measurement in relative humidity $R H$, and $G F_{l a b}$ is the growth factor of ammonium sul- phate particles in the same relative humidity $R H$, but measured in well defined laboratory conditions.

The second sequence of corrections was also based on laboratory data. Growth curves, i.e. growth factor vs. relative humidity of ammonium sulphate particles with diameters less than $30 \mathrm{~nm}$ have been determined in laboratory conditions. These growth curves, and to be more precise, their form has been used to predict the size into which the ambient particles, measured in relative humidity other than $90 \%$, would grow at $90 \% \mathrm{RH}$.

The correction procedure described above is based on the assumption that the ambient particles consisted of an ammonium sulphate volume together with insoluble material, which is of course is a simplification.

For this paper, only the data with DMA2 relative humidity 88-92\% (except for Luukki 1997 measurements 87\%-94\%) have been selected. Also for counting statistical reasons all observations during which concentrations after the DMA2 were lower than $0.1 \mathrm{~cm}^{-3}$ were discarded.

\subsection{Measurement sites}

The data presented in this work have been measured in urban, urban background, forest, and coastal environments. The data are from several separate field campaigns with focus on different scientific tasks. The urban, urban background and forest sites are located in Southern Finland, and the coastal site is located in Western Ireland.

The urban site is located in down town Helsinki. The aerosol sampling was done at the height of $20 \mathrm{~m}$ above sea level, and about $2 \mathrm{~m}$ above the ground level, with a distance of about $50 \mathrm{~m}$ to the closest road. The whole Helsinki down town area is surrounded by the sea and within the vicinity of the measurement site there is a bay. Air quality in Helsinki is affected mainly by traffic, energy production and the sea. The Helsinki data were measured in May 1998 and December 1999.

The urban background site, Luukki, is situated $22 \mathrm{~km}$ north-west from Helsinki and about $20 \mathrm{~km}$ north of the coast line. In Luukki the aerosol was sampled $5 \mathrm{~m}$ above the ground level. The site is surrounded by forests and agriculture and there are no significant local anthropogenic emission sources nearby. Distance to the closest road is about $1.5 \mathrm{~km}$. The concentrations of pollutants in Luukki are strongly affected by sources in Helsinki area. Meteorological conditions, especially the wind direction, radically alter the levels of gas and particle concentrations. Luukki is a measurement station used by the air quality authorities of Helsinki metropolitan area for continuous monitoring of urban background pollutants. The UF-TDMA measurements were performed in February 1997. More details about the downtown Helsinki and Luukki sites can be found in Hämeri et al. (1996), Buzorius et al. (1999) and Väkevä et al. (2000).

The forest site, Hyytiälä, is situated $250 \mathrm{~km}$ north-west from Helsinki. In Hyytiälä the sampling inlet was at the 
Table 1. Characteristics of the diurnal variations of growth factors of $10 \mathrm{~nm}$ particles measured at the urban site (Helsinki) in spring 1998 . The mean value for $G F$ is weighted with the concentration. The standard deviation is given in parenthesis. Actual ambient concentrations are two to three orders of magnitude higher than the DMA2 concentrations

\begin{tabular}{lllll}
\hline Mean $G F$ & mean min $G F$ & $\begin{array}{l}\text { Mean DMA2 conc }(\min G F) \\
\left(\mathrm{cm}^{-3}\right)\end{array}$ & mean max $G F$ & $\begin{array}{l}\text { mean DMA2 conc }(\max G F) \\
\left(\mathrm{cm}^{-3}\right)\end{array}$ \\
\hline $1.15(0.04)$ & $1.03(0.05)$ & 2.80 & $1.26(0.08)$ & 2.80 \\
\hline
\end{tabular}

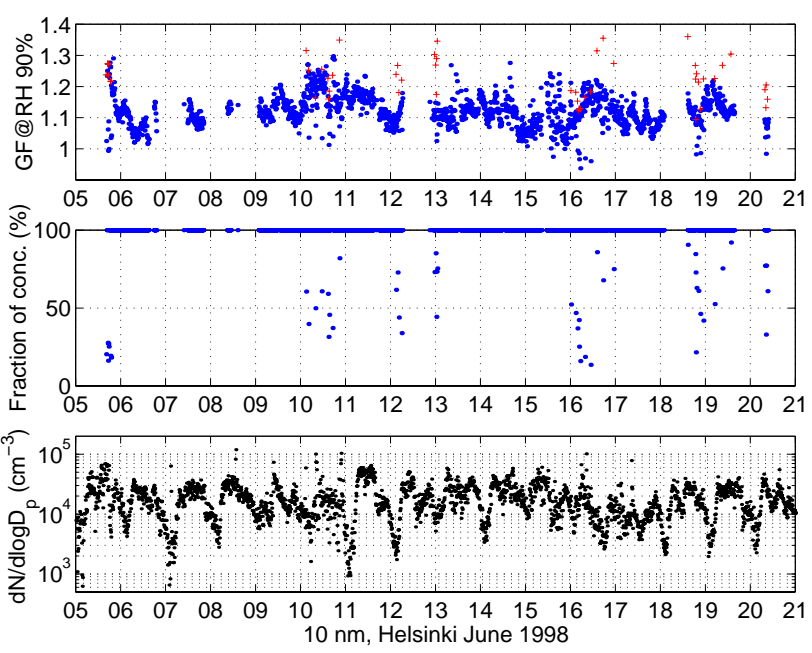

Fig. 1. UF-TDMA data of $10 \mathrm{~nm}$ particles measured in Helsinki May 1998 (the urban site). On top the growth factors (blue) at $90 \%$ relative humidity (the second mode during external mixing is plotted with red symbol), in the middle the concentration fraction of particles in the lower growth mode when external mixing was observed, and on the bottom the concentration of $10 \mathrm{~nm}$ particles $\left(d N / d \log D p, \mathrm{~cm}^{-3}\right)$ calculated using the DMPS data.

height of $67 \mathrm{~m}$ above the ground level. Hyytiälä SMEAR II station (a Station for Measuring Forest Ecosystem - Atmosphere Relations) is equipped with continuous monitoring of aerosol particle size distributions (DMPS, 3-800 $\mathrm{nm}$ in mobility diameter) together with a number of instruments measuring interactions between the forest and the atmosphere. For more information about Hyytiälä measurement station and measurements performed there see e.g. Mäkelä et al. (1997); Kulmala et al. (2001). Most of the Hyytiälä data presented in this paper were measured during the BIOFOR campaigns: April-May and August 1998, and March-April 1999 (Hämeri et al., 2001b).

The coastal measurements were done at Mace Head measurement station on the west coast of Ireland. The station has an excellent exposure to the North Atlantic. Most of the time clean marine background air surrounds the site. Only during winds from east or southeast, air is affected by local sources, such as bio-mass burning. For more information on the measurement site see for example O'Dowd et al. (2002).

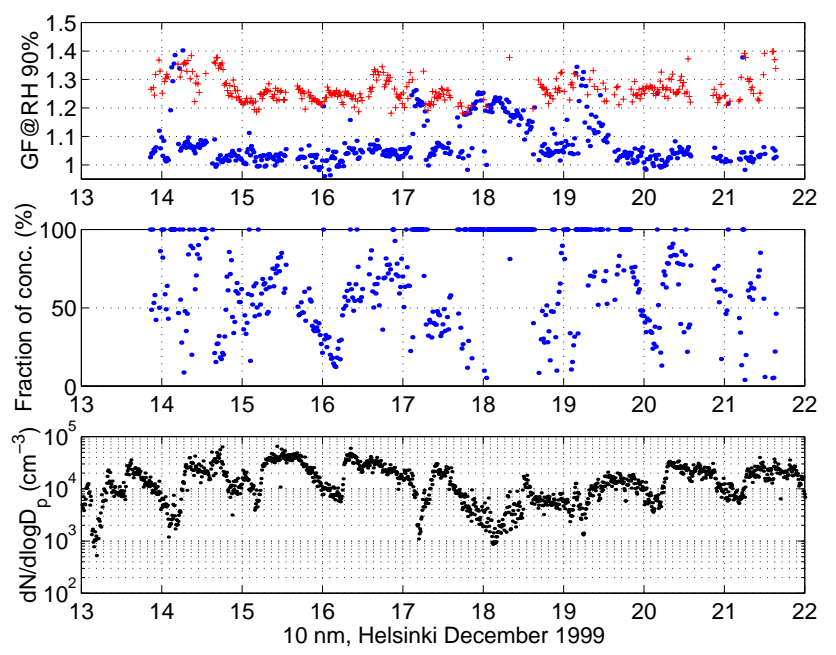

Fig. 2. UF-TDMA data of $10 \mathrm{~nm}$ particles measured in Helsinki December 1999 (the urban site). On top the growth factors (blue) at $90 \%$ relative humidity (the second mode during external mixing is plotted with red symbol), in the middle the concentration fraction of particles in the lower growth mode when external mixing was observed, and on the bottom the concentration of $10 \mathrm{~nm}$ particles $\left(d N / d \log D p, \mathrm{~cm}^{-3}\right)$ calculated using the DMPS data.

The UF-TDMA sampling was done from the height of $10 \mathrm{~m}$ and some tens of meters from the shoreline. These measurements were part of the PARFORCE campaigns in September 1998 and June 1999 (Väkevä et al., 2002).

\section{Results}

\subsection{Characteristic features and statistical properties}

\subsubsection{Urban site}

Data measured in Helsinki during the two weeks in May 1998 show that $10 \mathrm{~nm}$ particles were mostly internally mixed, with growth factors varying from about 0.95 to 1.36 (Fig. 1). The daily mean and mean of maximum and minimum values are presented in Table 1. Externally mixed particles were observed in $3.5 \%$ of all observations. The observed hygroscopic properties varied with time, but no obvious diurnal cycle was visible. Neither did air mass origin seem to affect 
Table 2. Observations of different growth modes in coastal site (Mace Head) during the summer measurements and urban site (Helsinki) during the winter 1999 measurements. The data are characterised with two modes. The presented concentrations are measured after DMA2, ambient concentrations $(d N / d \log D p)$ are approximately two to three orders of magnitude higher. Ext. Mix = frequency of observations of externally mixed particles (fraction of all observations), Mean $G F_{X}=$ mean growth factor of the mode, Mean conc $=$ mean concentration of mean $G F$ measured after DMA2, Of total conc = fraction of the total concentration (measured after DMA2) over the whole measurement period, Of total obs = fraction of all observations during the whole measurement period

\begin{tabular}{llllllllll}
\hline $10 \mathrm{~nm}$ & ext. mix. & mean $G F_{1}$ & $\begin{array}{l}\text { mean DMA2 } \\
\text { conc. }\left(\mathrm{cm}^{-3}\right)\end{array}$ & $\begin{array}{l}\text { of total } \\
\text { conc. }\end{array}$ & of all obs. & mean $G F_{2}$ & $\begin{array}{l}\text { Mean DMA2 } \\
\text { conc. }\left(\mathrm{cm}^{-3}\right)\end{array}$ & $\begin{array}{l}\text { of total } \\
\text { conc. }\end{array}$ & of total obs. \\
\hline Coastal 1998 & $6 \%$ & 1.07 & 4.43 & $31 \%$ & $25 \%$ & 1.27 & 2.31 & $70 \%$ & $74 \%$ \\
Coastal 1999 & $3 \%$ & 1.10 & 14.50 & $80 \%$ & $28 \%$ & 1.33 & 1.40 & $20 \%$ & $73 \%$ \\
Urban 1999 & $71 \%$ & 1.04 & 1.35 & $47 \%$ & $81 \%$ & 1.26 & 1.35 & $53 \%$ & $90 \%$ \\
\hline 20 nm & ext. mix. & mean $G F_{1}$ & mean DMA2 & of total & of all obs. & mean $G F_{2}$ & Mean DMA2 & of total & of total obs. \\
& & & conc. $\left(\mathrm{cm}^{-3}\right)$ & conc. & & & conc. $\left(\mathrm{cm}^{-3}\right)$ & conc. & \\
\hline Coastal 1999 & $8 \%$ & 1.11 & 0.91 & $4 \%$ & $8 \%$ & 1.43 & 2.11 & $96 \%$ & $92 \%$ \\
Urban 1999 & $87 \%$ & 1.04 & 1.50 & $52 \%$ & $99 \%$ & 1.27 & 1.50 & $48 \%$ & $91 \%$ \\
\hline
\end{tabular}
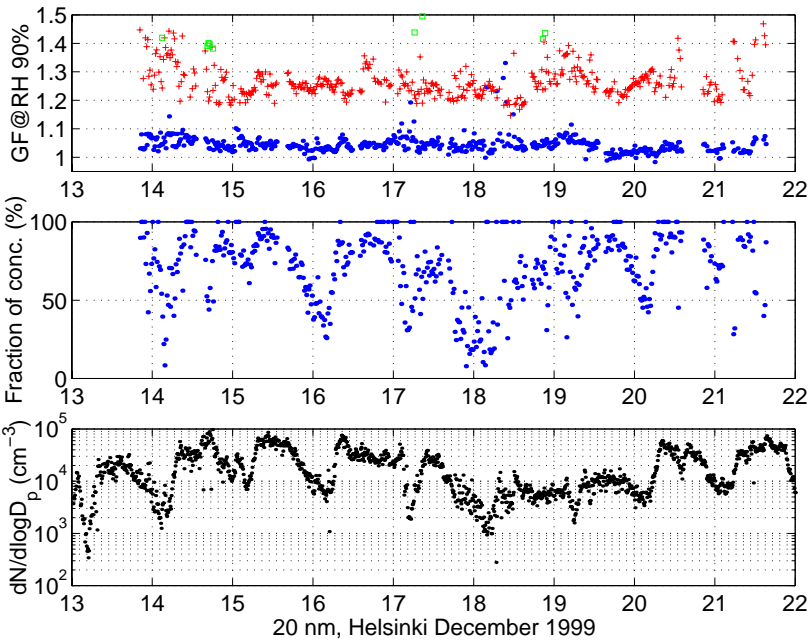

Fig. 3. UF-TDMA data of $20 \mathrm{~nm}$ particles measured in Helsinki December 1999 (the urban site). On top the growth factors (blue) at $90 \%$ relative humidity (the second mode during external mixing is plotted with red symbol and the third mode with green symbol), in the middle the concentration fraction of particles in the lower growth mode when external mixing was observed, and on the bottom the concentration of $20 \mathrm{~nm}$ particles $\left(d N / d \log D p, \mathrm{~cm}^{-3}\right)$ calculated using the DMPS data.

the observed growth factors. During two or several days with similar air mass trajectories the hygroscopic behaviour of nucleation mode particles varied considerably, and no air mass history-specific features could be determined. For the urban site the air mass trajectories were calculated using NOAA Air Resources Laboratory's web site (http : / / www . arl . noaa.gov/ss/models/hysplit.html).

Winter time measurements (December 1999) in Helsinki showed most of the time externally mixed particles. The $10 \mathrm{~nm}$ particles were externally mixed with two modes of hygroscopic growth in $71 \%$ of all observations (Fig. 2, and Table 2) and $20 \mathrm{~nm}$ particles in $87 \%$ of all observations (Fig. 3, and Table 2). Three $20 \mathrm{~nm}$ growth modes i.e. three different particle compositions were observed $2 \%$ of time. As shown in Table 2, $10 \mathrm{~nm}$ data during the measurement period can be described with two growth factors: mean growth factor 1.04 (std 0.03 , observed $81 \%$ of time) and mean growth factor 1.26 (std 0.05 , observed $90 \%$ of time). The observed $20 \mathrm{~nm}$ growth factors can be categorised as follows: mean growth factor 1.04, std 0.02 , was observed $99 \%$ of time, mean growth factor 1.27 , std 0.06 , was observed $91 \%$ of time.

The winter time growth factors of $10 \mathrm{~nm}$ particles ranged between $0.95-1.4$ and growth factors of $20 \mathrm{~nm}$ particles varied between $0.97-1.5$. Just as for the spring time observations, the growth factors did not seem to correlate with air mass history. The systematic occurrence of two hygroscopic growth modes during winter time indicates two (or more) different sources of particles both being similar in magnitude.

\subsubsection{Forest site}

In Hyytiälä, the measurements were made during three periods: April-May 1998 (data for 10 and $20 \mathrm{~nm}$ particles), July-August 1998 (20 nm particles), March-April 1999 (data for $10 \mathrm{~nm}$ and $20 \mathrm{~nm}$ particles). Several other dry sizes were studied during the Biofor campaign but only $10 \mathrm{~nm}$ and $20 \mathrm{~nm}$ data are presented in this paper.

Spring time growth factors of all measured sizes (also larger than $20 \mathrm{~nm}$, see Hämeri et al., 2001b) had a clear diurnal cycle. In general higher growth factors were detected during day time and lower during nights. The diurnal varia- 
Table 3. Characteristics of the diurnal variations of growth factors of $10 \mathrm{~nm}$ and $20 \mathrm{~nm}$ particles measured at the forest site (Hyytiälä) in spring 1999 over a time period of Arctic air masses. During the period the new particle events took place on 4-6, 8, 10 and 12-13 April

\begin{tabular}{ccccc}
\hline $\begin{array}{c}\text { Forest 1999 } \\
\text { Arctic air (3-13 April 1999) }\end{array}$ & mean min $G F$ & $\begin{array}{c}\text { Mean DMA2 conc } \\
\mathrm{cm}^{-3}\end{array}$ & mean max $F F$ & $\begin{array}{c}\text { mean DMA2 conc } \\
\mathrm{cm}^{-3}\end{array}$ \\
\hline $10 \mathrm{~nm}$ & 1.08 & 0.35 & 1.28 & 2.12 \\
$20 \mathrm{~nm}$ & 1.08 & 4.07 & 1.33 & 6.92 \\
\hline
\end{tabular}
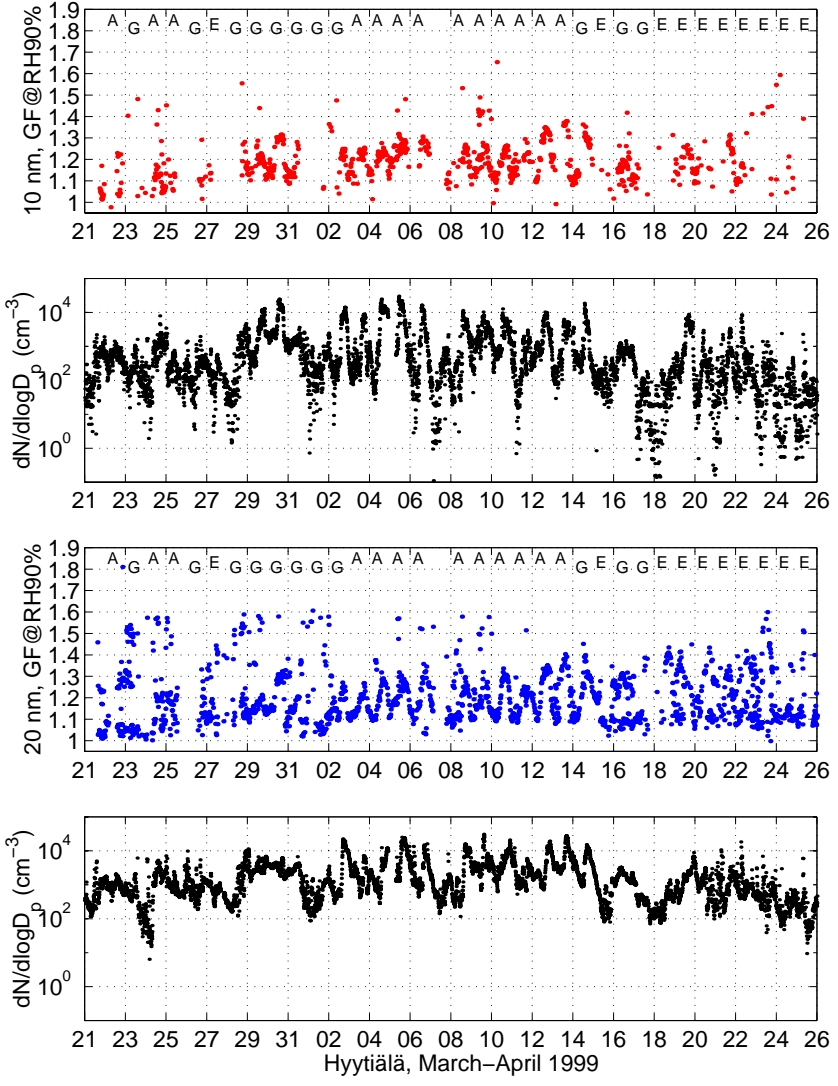

Fig. 4. Growth factors and concentrations of $10 \mathrm{~nm}$ (top two figures) and $20 \mathrm{~nm}$ particles in Hyytiälä March and April 1999. The concentrations of each size $\left(d N / d \log D p, \mathrm{~cm}^{-3}\right)$ are calculated using DMPS data. Also indicated are the air mass origins: $\mathrm{A}=$ Arctic, $\mathrm{E}=$ Middle Europe, $\mathrm{G}=$ Great Britain.

tions were particularly clear during days with Arctic air mass origin, as can be seen in Fig. 4. The daily mean highest and mean lowest growth factors for these days are presented in Table 3. For a detailed meteorological study of Biofor campaigns see Nilsson et al. (2001a) and Nilsson et al. (2001b). In air masses that were traced back to Great Britain or Central Europe externally mixed $20 \mathrm{~nm}$ particles were often observed. The frequency of observations of externally mixed particles seemed to increase the larger the measured size, e.g. in $199910 \mathrm{~nm}$ particles were externally mixed in 4\%, $20 \mathrm{~nm}$

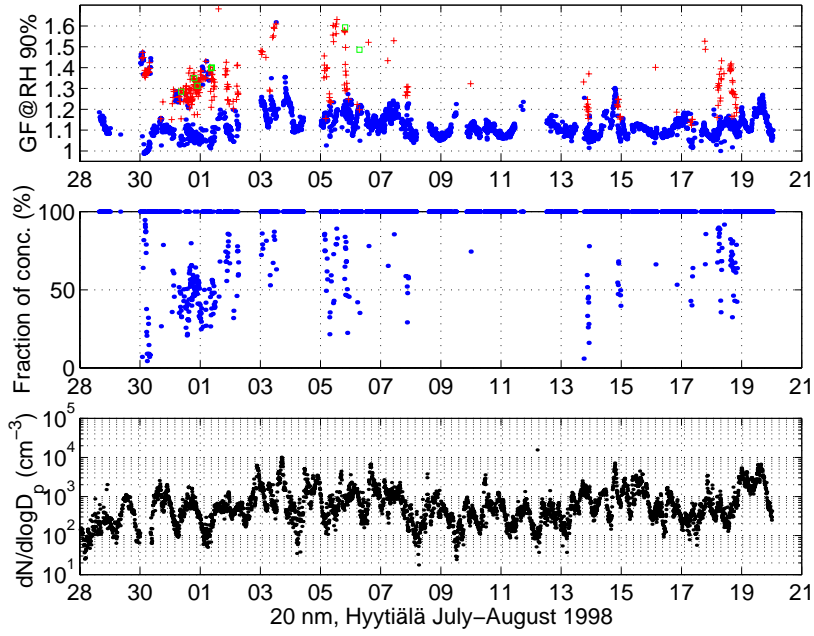

Fig. 5. UF-TDMA data of $20 \mathrm{~nm}$ particles in Hyytiälä July and August 1998 . On top the growth factors (blue) at $90 \%$ relative humidity (the second mode during external mixing is plotted with red symbol and the third mode with green symbol), in the middle the concentration fraction of particles in the lower growth mode when external mixing was observed, and on the bottom the concentration of $20 \mathrm{~nm}$ particles $\left(d N / d \log D p, \mathrm{~cm}^{-3}\right)$ calculated using the DMPS data

particles in $25 \%, 50 \mathrm{~nm}$ in $40 \%$ and $109 \mathrm{~nm}$ in $83 \%$ of all observations (Hämeri et al., 2001b). The growth factors of $10 \mathrm{~nm}$ particles ranged from 0.98 to 1.65 , and those of $20 \mathrm{~nm}$ from 0.99 to 1.81 .

In August 1998 (also few days in July) only $20 \mathrm{~nm}$ particles were studied, due to the very rare observations of $10 \mathrm{~nm}$ particles. Growth factors varied between 0.99 and 1.70 as can be seen in Fig. 5. Externally mixed particles were observed $13 \%$ of time, and there were also few incidents with three types of particles ( $0.3 \%$ of all measurements). Again observations of externally mixed particles were mostly connected to air masses arriving from polluted areas south-west.

\subsubsection{Urban background site}

Luukki measurement site which is located near Helsinki is strongly influenced by the local pollution in the area. However, during the periods of clean air masses originating typically from the north, the particle properties are expected to be similar to those at remote areas of Finland. During the 

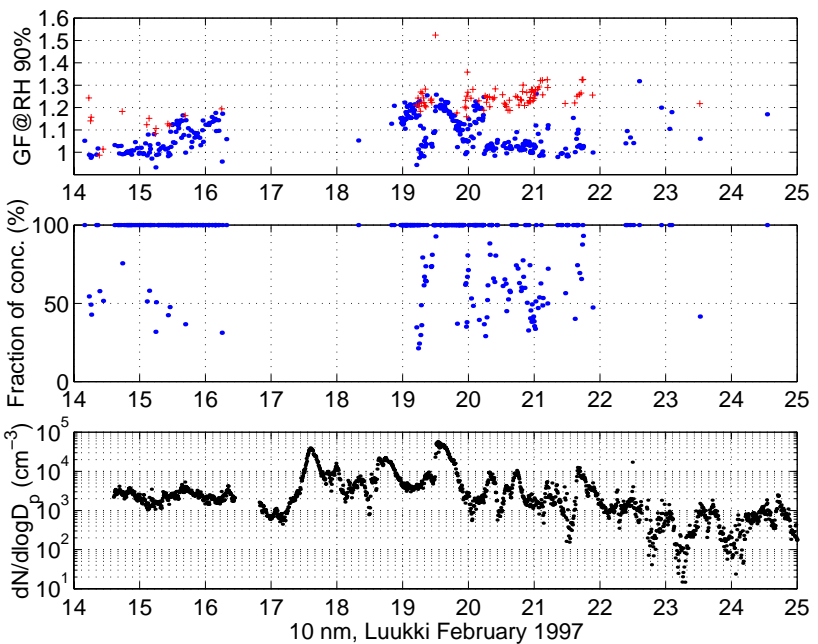

Fig. 6. UF-TDMA data of $10 \mathrm{~nm}$ particles in Luukki February 1997 (the urban background site). On top the growth factors (blue) at $90 \%$ relative humidity (the second mode during external mixing is plotted with red symbol), in the middle the concentration fraction of particles in the lower growth mode when external mixing was observed, and on the bottom the concentration of $10 \mathrm{~nm}$ particles $\left(d N / d \log D p, \mathrm{~cm}^{-3}\right)$ calculated using the DMPS data.

few days of UF-TDMA measurements in Luukki in February 1997, particle hygroscopic properties similar to the other measurement sites in Finland were observed (Fig. 6).

The growth factors on the first days of the measurement campaign are very scattered, as are the growth factors in Helsinki in May 1998. On the 20th and 21st of February, on the other hand, the data resemble measurements in Helsinki in December 1999 - when externally mixed particles were observed. During the measurement period, new particle formation events similar to the ones observed in the Hyytiälä forest field station were observed (the similarity is based on the DMPS data). Unfortunately valid UF-TDMA data is available for one of these days only - the 19th of February. The temporal variations in the hygroscopic properties of 10 $\mathrm{nm}$ particles during the nucleation event day were very similar to the nucleation event days in Hyytiälä: The growth factors are low in the morning prior to the nucleation event, they gradually increase just before and during the nucleation and decrease again in the afternoon (Hämeri et al., 2001b). The new particle formation events have been described in more detail in Väkevä et al. (2000).

\subsubsection{Coastal site}

The detected growth factors at the Mace Head measurement station were clearly dictated by the origin of studied air mass (Väkevä et al., 2002). The Mace Head data are presented in Fig. 7 and Fig. 8. When clean marine air was measured (westerly air flow) pre-existing $20 \mathrm{~nm}$ particles were hygroscopic with growth similar to or slightly less than pure am-
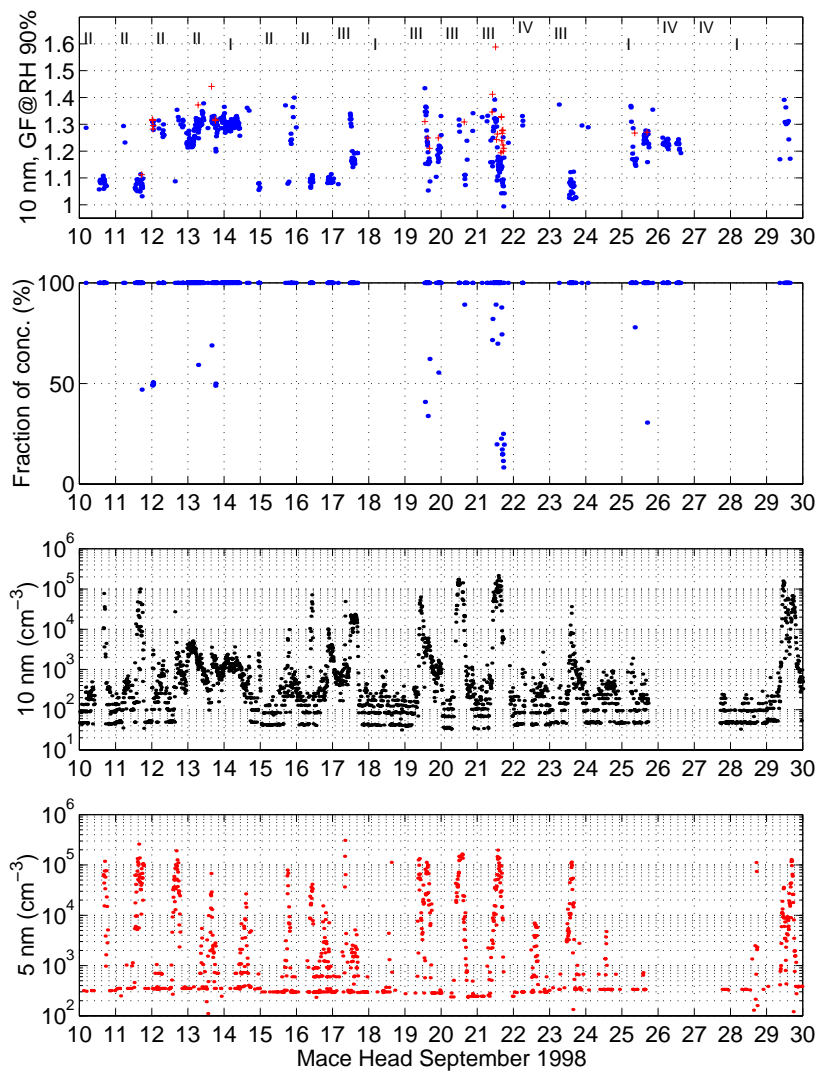

Fig. 7. UF-TDMA data of $10 \mathrm{~nm}$ particles in Mace Head (the coastal site) in September 1998. On top the growth factors (blue) at $90 \%$ relative humidity (the second mode during external mixing is plotted with red symbol), then the concentration fraction of particles in the lower growth mode when external mixing was observed, thirdly the concentration of $10 \mathrm{~nm}$ particles $\left(d N / d \log D p, \mathrm{~cm}^{-3}\right)$ calculated using the DMPS data. On the bottom the concentrations of $5 \mathrm{~nm}$ particles (DMPS data, $d N / d \log D p$ ) are shown - these data are presented as an indication of nucleation events, during which large numbers of $5 \mathrm{~nm}$ were detected. Particle formation event classification from O'Dowd et al. (2002): Type I clean marine air flow from the south to north west; Type II clean marine air but with advection over multiple tidal zones from northwest-to-north sector; Type III polluted air from the east to southerly sector and advecting over a tidal region $2-3 \mathrm{~km}$ from the station; Type IV conditions correspond to air trajectories with no advection of tidal regions; $U$ $=$ unclassified.

monium sulphate particles. On the other hand, the $10 \mathrm{~nm}$ (and $8 \mathrm{~nm}$ ) particles nucleated during the new particle formation events were hydrofobic, or had growth factors close to 1.0. These particles were observed in westerly air flow during low tide periods. In air masses that entered the measurement site through several coastal source regions during low tide periods, but were still of marine origin, diurnal cycle of the hygroscopic behaviour similar to Hyytiälä nucleation event days was detected.

In September 1998 growth factors of $10 \mathrm{~nm}$ particles var- 



Fig. 8. UF-TDMA data measured in Mace Head (the coastal site) in June 1999. Shown are the growth factors at $90 \%$ relative humidity of $10 \mathrm{~nm}$ and $20 \mathrm{~nm}$ particles, below which the concentration plot of both sizes $\left(d N / d \log D p, \mathrm{~cm}^{-3}\right)$ calculated using the DMPS data. On the bottom the concentrations of $5 \mathrm{~nm}$ particles (DMPS data, $d N / d \log D p)$ are shown - this data is presented as an indication of nucleation events, during which large numbers of $5 \mathrm{~nm}$ were detected. The particle formation event classification is presented in Fig. 7.

ied between 0.99 and 1.59, and in June $199910 \mathrm{~nm}$ growth factors varied between 0.97 and 1.97 , and $20 \mathrm{~nm}$ growth factors between 0.99 and 1.78. Also externally mixed particle populations were detected: during $199810 \mathrm{~nm} \mathrm{6 \%}$ of time, and during $199910 \mathrm{~nm} 3 \%$ and $20 \mathrm{~nm} 8 \%$ of time. A general conclusion was drawn that the externally mixed particles were connected to polluted air masses. The $20 \mathrm{~nm}$ particles affected by fresh combustion sources were non- or slightly hygroscopic, and the background marine particles more hygroscopic. On the other hand, freshly nucleated $10 \mathrm{~nm}$ particles that were formed in polluted air masses were hygroscopic. This was explained by abundant sulphuric acid concentrations (Berresheim et al., 2002).
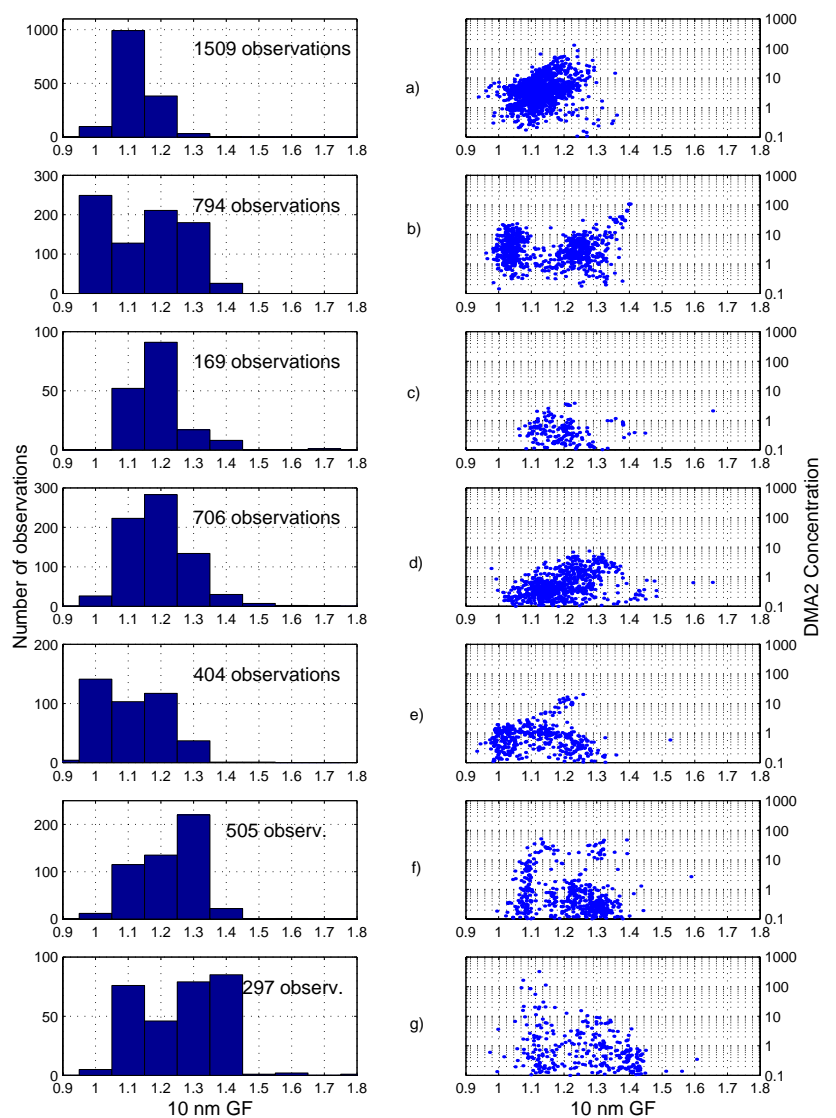

Fig. 9. Frequency of occurrence of different growth factors (left) and growth factors versus measured DMA2 concentrations (right) for $10 \mathrm{~nm}$ particles. The actual ambient $10 \mathrm{~nm}(d N / d \log D p)$ concentrations $\left(\mathrm{cm}^{-3}\right)$ are about three orders of magnitude larger than the presented values. (a) Helsinki May 1998; (b) Helsinki December 1999; (c) Hyytiälä April-May 1998; (d) Hyytiälä March-April 1999; (e) Luukki February 1997; (f) Mace Head September 1998; (g) Mace Head June 1999.

\subsection{Frequency of occurrence}

In Figs. 9 (10 nm data) and $10(20 \mathrm{~nm}$ data) the frequency distributions of the observed growth factors are presented. Also plotted (on the right panel) are the growth factors versus DMA2 concentrations for each measurement (the ambient concentrations are two to three orders of magnitude higher than the DMA2 concentrations). This is to show that, for instance for $10 \mathrm{~nm}$ particles in Luukki growth factor 1 was observed most frequently, but particles with growth factor of about 1.2 were most abundant in number concentration. Similarly also for Hyytiälä and Helsinki 1998 measurements; concentration weighed mean growth factors (over the whole measurement period) tend to be bigger than judging by just the number of observations. At both of these sites (Hyytiälä and Helsinki, 1998) a relatively wide range of growth factors was observed daily, and especially in Hyytiälä the high 


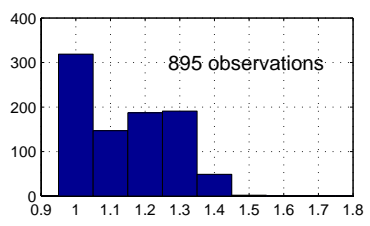

a)
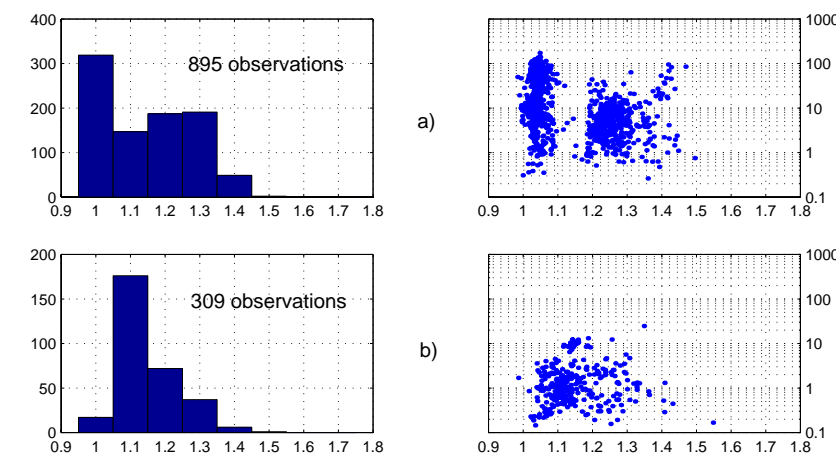

b)
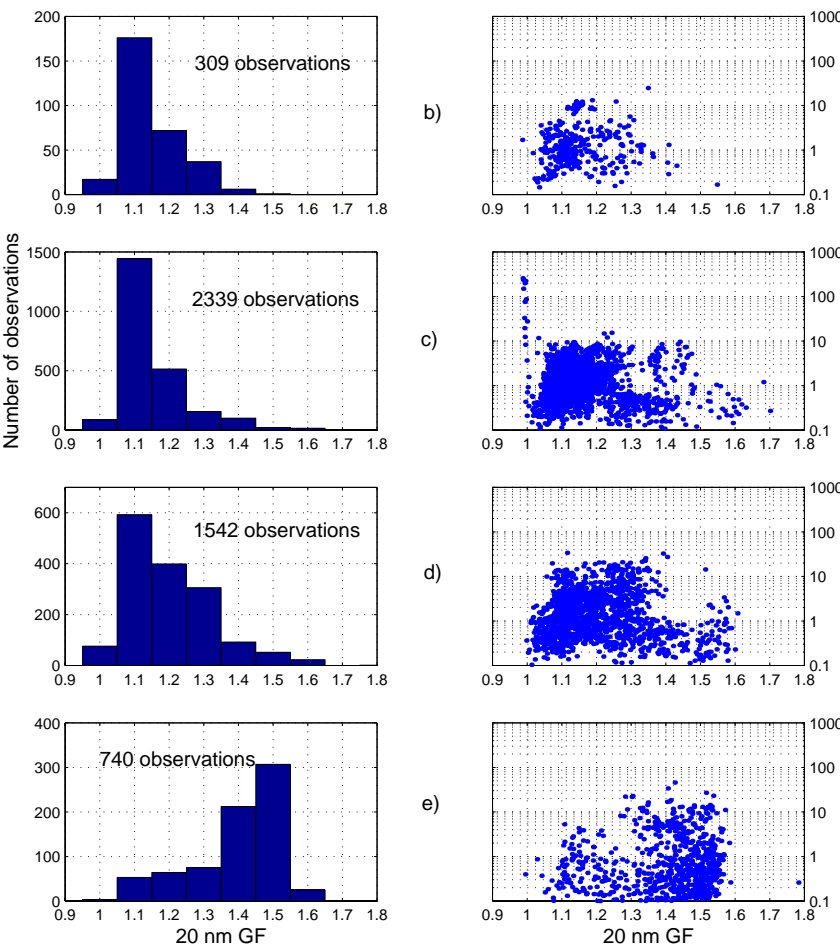

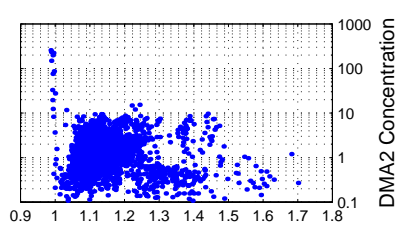

d)

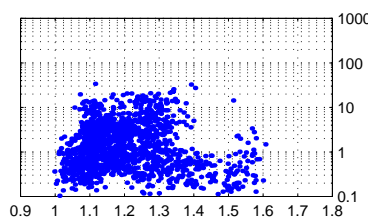

e)

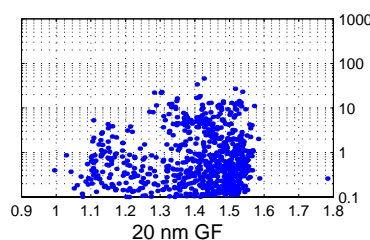

Fig. 10. Frequency of occurrence of different growth factors (left) and growth factors versus measured DMA2 concentrations (right) for $20 \mathrm{~nm}$ particles. The actual ambient $20 \mathrm{~nm}$ $(d N / d \log D p)$ concentrations $\left(\mathrm{cm}^{-3}\right)$ are about two orders of magnitude larger than the presented values. (a) Helsinki December 1999; (b) Hyytiälä April-May 1998; (c) Hyytiälä JulyAugust 1998; (d) Hyytiälä MarchApril 1999; (e) Mace Head June 1999.

growth factors were mostly observed during only few day time hours during which also the concentrations were at their highest. This is also the case for the nucleation day in Luukki (February 19th 1997). On this day the highest number concentrations during the whole measurement period were detected.

Comparison of $10 \mathrm{~nm}$ measurements performed in Helsinki in May and in December reveals major differences: in May "less hygroscopic" particles were observed systematically, and in December particles were externally mixed. What is noteworthy in Fig. 9 is that there seems to be a gap in December in just those growth factors that are most abundant in May. The anthropogenic sources in an urban area differ considerably between winter and summer owing to heating of buildings. However, the heat energy production in Helsinki downtown area is organised centrally in few power plants having high stacks and the emissions are detected in downtown area only with certain wind direction. The emissions from traffic are likely to be similar (although perhaps not equal in magnitude) during the whole year, but natural sources undoubtedly differ between summer and winter. Also meteorological conditions and atmospheric chemistry may significantly alter the behaviour of precursor gases and condensable vapours between the summer and winter time measurement periods.

Hygroscopic properties of the $20 \mathrm{~nm}$ particles (Fig. 10) have clear differences between the measurement sites: hygroscopic particles in Mace Head (coastal site) have higher growth factors than in the other sites. The observed growth factors indicate that these particles contain an inorganic salt compound (growth factor similar to ammonium sulphate). On the other hand, Helsinki is also situated on the shoreline, and therefore the observed hygroscopic particles might contain similar compounds to the Mace Head particles. The observed growth factors of hygroscopic particles in Helsinki are, however, smaller than in Mace Head. This does not necessarily rule out similarities: salt particles in Helsinki might be coated with, e.g. hydrocarbons from traffic and other combustion processes that affect their water solubility (Hansson et al., 1998; Xiong et al., 1998). Another potential explanation is that the higher growth mode in Helsinki results from ageing: originally less-hygroscopic particles tend to gain soluble properties when aged (e.g. Cocker et al., 2001; Swietlicki et al., 2000). If this is the case also the $10 \mathrm{~nm}$ particles (or the vapours that condensed on both particle sizes) have undergone a similar ageing process, since in December 1999 
both 10 and $20 \mathrm{~nm}$ particles are very similar with respect to hygroscopic properties. Unfortunately UF-TDMA measurements of $20 \mathrm{~nm}$ particles are not available in Helsinki during summer time.

The hygroscopic properties of aerosol population are typically used as input values in state-of-art aerosol dynamical models (see Pirjola and Kulmala, 2001) and cloud microphysical models (see Kulmala et al., 1996). Therefore typical growth factors, and DMA2 concentrations of different hygroscopic modes are given in Tables 1, 2 and 3. The two mode behaviour in urban air can clearly be seen from Table 2 for both 10 and $20 \mathrm{~nm}$ particles. On the other hand the behaviour of $10 \mathrm{~nm}$ and $20 \mathrm{~nm}$ in coastal environment differs from each other.

\section{Summary and conclusions}

In all of the studied sites a background population of nucleation mode particles was observed frequently, but also a number of particle formation events was observed. In the urban site the anthropogenic fraction of nucleation mode particles dominates the lower end of the size distribution. The characteristics of the nucleation events are described in, e.g. Mäkelä et al. (1997), O’Dowd et al. (1998) and Väkevä et al. (2000). Apparently, the nucleation in atmosphere is important source for new particles. The relative importance of nucleation events in controlling the nucleation mode particle population varies between the sites. Especially in urban air, the anthropogenic fraction dominates the $10 \mathrm{~nm}$ particle population most of the time. The multiple sources of nucleation mode particles are observable as external mixture of the aerosol. This was observed in all the measurement sites. However, the external mixing was much more frequent in urban air compared with background air both in coastal and forest site.

The atmospheric aerosols are generally classified into four classes based on their hygroscopicity. The background of the growth factor classification is based on the earlier work for larger particles by other researchers, e.g. Swietlicki et al. (1999). Using the observations presented in this paper our aim was to investigate if similar classification is practical also for the nucleation mode particles. It should be noted that as the Kelvin correction for curvature is significant at this size range, the absolute values of the growth factors are lower than for accumulation mode particles. Some of the growth factor classes were obvious when studying the data sets: e.g. hydrophobic $10 \mathrm{~nm}$ particles were observed during the nucleation events at the coastal site $(G F=1)$. During the occasions of externally mixed particles in downtown Helsinki in the winter of 1999, the less hygroscopic $10 \mathrm{~nm}$ particles had growth factors ranging between 1.0 and 1.1 and the more hygroscopic particles between 1.2 and 1.4. Also when externally mixed particles were observed at the coastal site the more hygroscopic mode had growth factors in the range 1.2-
1.4 or higher. Those particles with growth factors higher than 1.4 were classified as sea salt, due to their hygroscopic properties resembling $\mathrm{NaCl}$ particles. Thus we suggest that the classification of nucleation mode particles is also based on four categories with the following values: the non hygroscopic particles, with growth factor 1; the less-hygroscopic particles with growth factors ranging between 1.05 and 1.2; the more hygroscopic particles, with growth factors 1.2-1.4; and the sea salt particles, with growth factors larger than 1.4. In all the studied locations, the growth factors varied within these categories, however, most often between 1.0 and 1.4.

Low growth factors were occasionally detected at all sites, but especially connected with the urban measurements growth factors lower that 1 were observed. Growth factors lower than unity could be explained by soot or other aggregated particles that collapse when interacting with water vapour at high relative humidities. On the other hand, the values lower than 1 are typically within the accuracy of the experiments.

The growth factors that are only slightly larger than unity may partly be explained by adsorption of layers of water molecules on the particle surface. This phenomenon is more pronounced for small particle sizes and is experimentally verified for 10-20 nm particles using an UF-TDMA setup. Adsorption of water on nucleation mode particles using UFTDMA data is discussed in detail by Romakkaniemi et al. (2001).

Based on the UF-TDMA studies $10 \mathrm{~nm}$ and $20 \mathrm{~nm}$ particles have similar hygroscopic properties in urban (winter time) environment. Both the magnitude and the bimodal structure of the hygroscopic growth factors are similar for both sizes, when Kelvin effect due to the curvature of the particle surface is taken into account. The likely explanation is that most of the time both particle sizes belong to the same size mode and have same origin and composition.

In forest environment the diurnal behaviour with higher growth factors at day time and low at night time is also similar for both $10 \mathrm{~nm}$ and $20 \mathrm{~nm}$ particles. As in the urban site, also in forest environment both particle sizes belonged to the same size mode most of the time. During the most intensive nucleation events, the whole nucleation mode was in the beginning below $20 \mathrm{~nm}$. However, the condensable vapour that grew the nucleated particles into observable size of $10 \mathrm{~nm}$ was probably condensing also on the surfaces of the preexisting particles, as during those periods the pre-existing $20 \mathrm{~nm}$ particles showed also hygroscopic properties similar to freshly nucleated $10 \mathrm{~nm}$ particles.

The coastal measurements showed systematically that the $20 \mathrm{~nm}$ particles were hygroscopic, whereas the freshly nucleated $10 \mathrm{~nm}$ particles were non-hygroscopic. The coastal observations during which $10 \mathrm{~nm}$ and $20 \mathrm{~nm}$ particles were clearly of different composition, are explained by different sources and ages of the particles. Particles that are formed during the coastal nucleation events consist of hydrofobic material. Whether this is the compound that originally was 
responsible for the formation of the particles, or if some hydrofobic vapour condensed on the stable clusters and grew them to $10 \mathrm{~nm}$ particles, can not be distinguished based on UF-TDMA measurements. During the most intense nucleation events the growth factors of $20 \mathrm{~nm}$ particles were also seen to decrease. This is an indication that there was a very strong source of hydrofobic vapour available, and the vapour also condensed on the pre-existing particles.

The urban site was the only one where the air mass origin did not seem to affect the hygroscopic growth behaviour of the studied particle sizes.

In the coastal site, Mace Head, the growth factors were obviously affected by air mass history: Nucleation events in clean coastal air produced particles with low growth factors. When air mass was possibly influenced by several source regions of condensable gases - yet clean air - diurnal temporal variations of growth factors resembled measurements in the forest site. When polluted air was detected growth factors varied just like in Helsinki during the May 1998 period. It should also be noted that during the September 1998 measurements in Mace Head smaller growth factors were detected than in June 1999. This difference is explained possibly by differences in the condensing vapours or meteorological conditions. This assumption was also backed by the cloud condensation nucleus counter (CCNC) measurements performed at the site during both the periods: in June Aitken and accumulation mode particles were also more soluble than the ones measured in September (Väkevä et al., 2002).

At the forest site, Hyytiälä, air mass history seemed to have an effect on growth factors. This was most evident in observations of external mixing. When air masses originated from south-west (especially from western Atlantic over Great Britain) externally mixed $20 \mathrm{~nm}$ particles were often detected. When backward trajectories originated from Great Britain, the growth factors of the more hygroscopic mode were of the same magnitude as in Mace Head. When external mixing was observed in air masses traced back to Central Europe, both hygroscopic modes showed temporal variations. On the average particles belonging to both modes were more soluble during day time than at night. One possible explanation for this is chemical transformation of the composition of the particles or condensing vapours due to oxidation and air chemistry. The origin of air masses seemed crucial also for the nucleation events, which mostly occurred in Arctic air (Nilsson et al., 2001b). However, diurnal pattern of hygroscopic properties of nucleation mode particles $(10 \mathrm{~nm})$ was detected even during days with no observable new particle formation.

Acknowledgements. The financial support from European Commission Environment and Climate Programme contracts ENV4CT97-0405 (BIOFOR) and ENV4-CT97-0526 (PARFORCE) are acknowledged.

\section{References}

Berresheim, H., Elste, T., Tremmel, H. G., O’Dowd, C. D., Allen, A. G., Hansson, H.-C., Rosman, K., Dal Maso, M., Mäkelä, J. M., and Kulmala, M.: Gas-Aerosol relationships of H2SO4, MSA, and $\mathrm{OH}$ : Observations in the Coastal Marine Boundary Layer at Mace Head, Ireland, J. Geophys. Res., in press, 2002.

Birmili, W. and Wiedensohler, A.: New particle formation in the continental boundary layer: Meteorological and gas phase parameter influence, Geophys. Res. Lett., 27, 3325-3328, 2000.

Buzorius, G., Hämeri, K., Pekkanen, J., and Kulmala, M.: Spatial variation of aerosol number concentration in Helsinki city, Atmos. Environ., 33, 553-565, 1999.

Cocker, D. R., Whitlock, N. E., Flagan, R. C., and Seinfeld, J.: Hygroscopic properties of Pasadena, California Aerosol, Aerosol Sci. Technol., 35, 637-647, 2001.

Covert, D. S. and Heintzenberg, J.: Size distributions and chemical properties of aerosol at Ny Ålesund, Svalbard, Atmos. Environ., 27A, 2989-2997, 1993.

Djikaev, Y. S., Bowles, R., Reiss, H., Hämeri, K., Laaksonen, A., and Väkevä, M.: Theory of size dependent deliquescence of nanoparticles: Relation to heterogeneous nucleation and comparison with experiments, J. Phys. Chem. B, 105, 7708-7722, 2001.

Hansson, H.-C., Wiedensohler, A., Koloutsou-Vakakis, S., Hämeri, K., and Orsini, D.: $\mathrm{NaCl}$ aerosol particle hygroscopicity dependence on mixing with organic compounds, J. Atmos. Chem., 31, 321-346, 1998.

Hämeri, K., Kulmala, M., Aalto, P., Leszczynski, K., Visuri, R., and Hämekoski, K.: The investigations of aerosol particle formation in urban background area of Helsinki, Atmospheric Research, 41, 281-298, 1996.

Hämeri, K., Väkevä, M., Hansson, H.-C., and Laaksonen, A.: Hygroscopic growth of ultrafine ammonium sulphate aerosol measured using an ultrafine tandem differential mobility analyser, J. Geophys. Res., 105, 22 231-22 242, 2000.

Hämeri, K., Laaksonen, A., Väkevä, M., and Suni, T.: Hygroscopic growth of ultrafine sodium chloride particles, J. Geophys. Res., 106, 20 749-20 758, 2001a.

Hämeri, K., Väkevä, M., Aalto, P. P., Kulmala, M., Swietlicki, E., Zhou, J., Seidl, W., Becker, E., and O’Dowd, C. D.: Hygroscopic and $\mathrm{CCN}$ properties of aerosol particles in boreal forest, Tellus, 53B, 359-379, 2001b.

Kulmala, M., Korhonen, P., Vesala, T., Hansson, H.-C., Noone, K., and Svenningsson, B.: The effect of hygroscopicity on cloud droplet formation, Tellus, 48B, 347-360, 1996.

Kulmala, M., Hämeri, K., Aalto, P. P., Mäkelä, J.M., Pirjola, L., Nilsson, E. D., Buzorius, G., Rannik, Ü., Dal Maso, M., Seidl, W., Hoffmann, T., Janson, R., Hansson, H.-C., Viisanen, Y., Laaksonen, A., and O'Dowd, C. D.: Overview of the international project on biogenic aerosol formation in the boreal forest (BIOFOR), Tellus, 53B, 324-343, 2001.

McMurry, P.H. and Stolzenburg, M.R.: On the sensitivity of paricle size to relative humidity for Los Angeles aerosols, Atmos. Environ., 23, 497-507, 1989.

Mäkelä, J. M., Aalto, P., Jokinen, V., Pohja, T., Nissinen, A., Palmroth, S., Markkanen, T., Seitsonen, K., Lihavainen, H., and Kulmala, M.: Observations of ultrafine aerosol particle formation and growth in boreal forest, Geophys. Res. Lett., 24, 1219-1222, 1997. 
Nilsson, E. D., Rannik, Ü., Kulmala, M., Buzorius, G., and O'Dowd, C. D.: Effect of the continental boundary layer evolution, convection, turbulence and entrainment on aerosol formation, Tellus, 53B, 441-461, 2001a.

Nilsson, E. D., Paatero, J., and Boy, M.: Effects of air masses and synoptic weather on aerosol formation in the continental boundary layer, Tellus, 53B, 462-478, 2001b.

O'Dowd, C.D., Geever, M., Hill, M.K., Smith, M.H., and Jennings, S. G.: New particle formation and spatial scales in the clean marine coastal environment, Geophys. Res. Lett., 25, 1661-1664, 1998.

O’Dowd, C. D., Hämeri, K., Mäkelä, J. M., Väkevä, M., Aalto, P. P., de Leeuw, G., Kunz, G. J., Becker, E., Hansson, H.-C., Allen, A. G., Harrison, R. M., Berresheim, H., Kleefeld, C., Geever, M., Jennings, S. G., and Kulmala, M.: Coastal new particle formation: Environmental conditions and aerosol physico-chemical characteristics during nucleation bursts, J. Geophys. Res., in press, 2002.

Pirjola, L. and Kulmala, M.: Development of particle size and composition distributions with a novel aerosol dynamics model, Tellus, 53B, 491-509, 2001.

Romakkaniemi, S., Hämeri, K., Väkevä, M., and Laaksonen, A.: Adsorption of water on $8-15 \mathrm{~nm} \mathrm{NaCl}$ and $\left(\mathrm{NH}_{4}\right)_{2} \mathrm{SO}_{4}$ aerosols measured using an ultrafine tamdem differential mobility analyzer, J. Phys. Chem. A, 105, 8183-8188, 2001.

Stratmann, F., Orsini, D., and Kauffeldt, Th.: Inversion algorithm for TDMA measurements, J. Aerosol Sci. 28 S1, 701-702, 1997.

Svenningsson, B., Hansson, H.-C., and Wiedensohler, A.: Hygroscopic growth of aerosol particles in the Po Valley, Tellus, 44B,
556-569, 1992.

Swietlicki, E., Zhou, J., Berg, O. H., Martinsson, B. G., Frank, G., Cederfelt, S.-I., Dusek, U., Berner, A., Birmili, W., Wiedensohler, A., Yuskiewicz, B., and Bower, K. N.: A closure study of sub-micrometer aerosol particle hygroscopic behaviour, Atmospheric Research, 50, 205-240, 1999.

Swietlicki, E., Zhou, J., Covert, D. S., Hämeri, K., Busch, B., Väkevä, M., Dusek, U., Berg, O. H., Wiedensohler, A., Aalto, P., Mäkelä, J., Martinsson, B. G., Papaspiropoulos, G., Mentes, B., Frank, G., and Stratmann, F.: Hygroscopic properties of aerosol particles in the north-eastern Atlantic during ACE-2, Tellus, 52B, 201-227, 2000.

Väkevä, M., Hämeri, K., Puhakka, T., Nilsson, E. D., Hohti, H., and Mäkelä, J.M.: Effects of meteorological processes on aerosol particle size distribution in an urban background area, J. Geophys. Res., 105, 9807-9821, 2000.

Väkevä, M., Hämeri, K., and Aalto, P. P.: Hygroscopic properties of nucleation mode and Aitken mode particles during nucleation bursts and in background air on west coast of Ireland, J. Geophys. Res., in press, 2002.

Yuskiewicz, B., Stratmann, F., and Kauffeldt, Th.: Resolution of a TDMA-inversion algorithm, J. Aerosol Sci., 29 S1, 1245-1246, 1998.

Xiong, J. Q., Zhong, M., Fang, C., Chen, L. C., and Lippmann, M.: Influence of organic films on the hygroscopicity of ultrafine sulfuric acid aerosol, Environ. Sci. Technol., 32, 3536-3541, 1998.

BIOFOR: http://www.mist.helsinki.fi/Projects/Project.html\#biofor PARFORCE: http://www.macehead.physics.nuigalway.ie/parforce/ 